\title{
TOTAL OXIDANT STATUS, TOTAL ANTIOXIDANT STATUS, AND PARAOXONASE AND ARYLESTERASE ACTIVITIES DURING LAPAROSCOPIC CHOLECYSTECTOMY
}

\author{
Hande Koksal, ${ }^{\text {I Sevil Kurban }}{ }^{\text {II }}$ \\ doi: $10.1590 / \mathbf{S 1 8 0 7 - 5 9 3 2 2 0 1 0 0 0 0 3 0 0 0 0 8}$
}

\begin{abstract}
Koksal H, Kurban S. Total oxidant status, total antioxidant status, and paraoxonase and arylesterase activities during laparoscopic cholecystectomy. Clinics. 2010;65(3):285-90.
\end{abstract}

INTRODUCTION: Laparoscopic cholecystectomy is the gold standard for the treatment of gallstone disease; however, adverse hemodynamic changes induced by increased intraabdominal pressure due to pneumoperitoneum are known to occur. Herein, we investigated the effects of pneumoperitoneum on oxidative stress markers, including paraoxonase, arylesterase, total oxidant status, and total antioxidant status, during laparoscopic cholecystectomy.

PATIENTS AND METHODS: Patients that underwent a laparoscopic cholecystectomy were classified as Group I, whereas patients that underwent surgical procedures for an abdominal wall hernia under general anesthesia were classified as Group II. Blood samples were obtained during the preoperative period, the perioperative period, and 24 hours after surgery (postoperative day 1). Leukocyte counts, neutrophil rates, paraoxonase activities, arylesterase activities, and total oxidant and antioxidant status levels were measured. RESULTS: The differences in leukocyte counts and neutrophil rates were not significant between the two groups. In Group I, no significant differences in the total oxidant and antioxidant status levels were identified; however, paraoxonase and arylesterase levels were lower on postoperative day 1 . No significant changes were observed in the total oxidant status, total antioxidant status, and paraoxonase or arylesterase activities in Group II. The perioperative total antioxidant status and arylesterase level were higher in Group I in comparison to Group II.

CONCLUSION: Paraoxonase and arylesterase levels are useful markers in the evaluation of oxidative stress caused by intraabdominal pressure due to pneumoperitoneum.

KEYWORDS: Laparoscopy; Cholecystectomy; Paraoxonase; Arylesterase; Oxidative markers.

\section{INTRODUCTION}

Laparoscopic cholecystectomy (LC), a minimally invasive procedure in which the gallbladder is removed, is a common operation and has gained worldwide acceptance as the gold standard surgical method to treat gallstone disease. ${ }^{1}$ Adverse hemodynamic changes associated with LC, such as reduced venous return and increased

${ }^{\mathrm{I}}$ Department of General Surgery, Konya Numune State Hospital - Konya, Turkey.

II Department of Biochemistry, Meram Faculty of Medicine, Selcuk University - Konya, Turkey. Email: drhandeniz@yahoo.com

Tel.: +90332 $2354500 / 5372$

Received for publication on October 06, 2009

Accepted for publication on December 28, 2009 systemic vascular resistance, have primarily been linked to the increase in intraabdominal pressure (IAP) caused by pneumoperitoneum. ${ }^{2-7}$ Reduced abdominal visceral perfusion and portal venous flow have also been shown to occur in patients who underwent LC. ${ }^{8-11}$ This reduction in abdominal visceral perfusion could be an important cause of oxidative stress during laparoscopic surgical procedures. ${ }^{12-15}$

Paraoxonase (PON1) is an ester hydrolase that has both arylesterase and paraoxonase activities. Recently, roles for PON1 in a number of processes have been studied, including lipid and lipoprotein metabolism, as well as for their antiatherogenic and antioxidant properties. ${ }^{16-20}$ Oxidative stress, which is the result of an increased number of lipid and protein oxidation products and decreased number of antioxidant enzymes and vitamins, has been 
reported to affect the expression and activities of PON1. ${ }^{16}$, ${ }^{20}$ Furthermore, oxidative stress has been shown to decrease PON1 activity and down-regulate the serum expression of PON1. ${ }^{16,21-24}$

In the present clinical study, we aimed to investigate the effects of pneumoperitoneum on oxidative stress markers during LC, including paraoxonase activity, total oxidant status (TOS) and total antioxidant status (TAS).

\section{MATERIALS AND METHODS}

This study was performed in Konya Numune State Hospital. Group I patients underwent an LC procedure, whereas Group II patients underwent surgical procedures to treat abdominal wall hernias under general anesthesia. The presence of any of the following conditions was used as an exclusion criterion in this study: diabetes mellitus, neoplastic disease, inflammatory disease (such as infections and autoimmune disorders), hypercholesterolemia, hypertriglyceridemia, use of an antihypertensive medication, lipid-lowering drug use, antioxidant substance use, known secondary hypertension, chronic renal failure, cerebrovascular disease, ischemic heart disease, congestive heart failure, gastrointestinal disease or liver disease.

The study protocol was approved by the Ethics Committee of the Meram Faculty of Medicine, Selcuk University, and was conducted according to the Declaration of Helsinki, Good Clinical Practice Guidelines. The participants were informed about the nature of the study and informed consents were obtained.

Blood samples were obtained preoperative, perioperative, and 24 hours after surgery (postoperative day 1). Serum specimens were centrifuged for $15 \mathrm{~min}$ at $3000 \mathrm{rpm}$, transferred to Eppendorf tubes, and stored at $-80^{\circ} \mathrm{C}$. The specimens were used to measure paraoxonase activity, TOS and TAS.

\section{Measurement of paraoxonase and arylesterase activities}

Paraoxonase and arylesterase activities were measured by using paraoxon and phenylacetate as the substrates, respectively. The basal activity of paraoxonase was measured. The rate of paraoxon hydrolysis (diethyl-pnitrophenylphosphate) was measured by monitoring an increase in absorbance at $412 \mathrm{~nm}$ at $37^{\circ} \mathrm{C}$ on an autoanalyser (Beckman Coulter, Fullerton, CA, U.S.A.). The amount of generated p-nitrophenpl was calculated from the molar absorptivity coefficient at a $\mathrm{pH}$ of 8.5 , which was 18290 $\mathrm{M}^{-1} \mathrm{~cm}^{-1} .{ }^{20}$ Paraoxonase activity is expressed as $\mathrm{U} / \mathrm{L}$ of serum. Phenylacetate was used as the substrate to measure arylesterase activity. One unit of arylesterase activity was defined as $1 \mu \mathrm{mol}$ of phenol generated per min and is expressed as $\mathrm{U} / \mathrm{L}$ of serum. ${ }^{25}$

\section{Measurement of the total antioxidant status}

The TAS levels of the sera were determined using an automated measurement method based on bleaching of the characteristic color of a more s 2,2'-azino-bis [3-ethylbenzthiazoline-6-sulfonic acid (ABTS)] radical cation caused by antioxidants. ${ }^{26}$ The results are expressed in mmol Trolox equivalents/L.

\section{Measurement of total oxidant status}

The TOS levels of the sera were determined using a novel automated measurement method. ${ }^{27}$ Oxidants present in the sample oxidize the ferrous ion-o-dianisidine complexes into ferric ions. The oxidation reaction is enhanced by glycerol molecules that are abundantly present in the reaction medium. The ferric ions form a colored complex with xylenol orange in an acidic medium. Therefore, the color intensity, measured spectrophotometrically, is related to the total number of oxidant molecules present in the sample. The assay is calibrated with hydrogen peroxide and the results are expressed in terms of micromolar hydrogen peroxide equivalent per liter $\left(\mu \mathrm{mol} \mathrm{H}_{2} \mathrm{O}_{2}\right.$ equiv./L).

\section{Statistical analysis}

Statistical analysis was performed using SPSS software for Windows, release 13.0. Results are expressed as the mean \pm standard deviation (SD). Statistical analysis was performed using the Mann-Whitney $U$ test and Paired $t$-test. Statistical significance was assumed at a level of $P<0.05$.

\section{RESULTS}

The study presented here contained 20 patients who underwent an LC (Group I) and 10 patients who underwent a surgical procedure to treat an abdominal wall hernia under general anesthesia (Group II). In Group I, the median patient age was 49.5 years of age (range, 26-77 years), and 16 of the patients were female and 4 were male. In Group II, the median age was 44.5 years of age (range, 17-52 years), and five of the patients were female and five were male. In Group II, the diagnoses of the patients were either a groin or an umbilical hernia. Mean operation times for Groups I and II were $33.63 \pm 11.03$ and $46.2 \pm 21.1 \mathrm{~min}$, respectively. The difference in the respective mean operation times of the two groups was not statistically significant $(\mathrm{p}=0.22)$. 


\section{Leukocyte counts and neutrophil rates}

The leukocyte counts and neutrophil rates in Groups I and II are shown in Table 1.

In Group I, leukocyte counts in the perioperative period and on postoperative day 1 were higher than those during the preoperative period for both groups $(\mathrm{p}=0.013$ and $\mathrm{p}=0.016$, respectively). In Group II, the differences in leukocyte counts during the preoperative period, perioperative period, and on postoperative day 1 were not significant.

The neutrophil rates on postoperative day 1 were higher than those during the preoperative period for both Groups I and II ( $\mathrm{p}=0.001$ and $\mathrm{p}=0.009$, respectively).

\section{Oxidative stress markers}

Mean and SD values of PON1 and arylesterase activities, as well as TAS and TOS levels are presented in Table 2.
No significant differences in TOS and TAS levels in Group I were observed. For Group I, the paraoxonase level on postoperative day 1 was significantly lower than the paraoxonase level during the preoperative period ( $\mathrm{p}=0.035)$. Furthermore, the arylesterase activity in Group I during the preoperative period was higher than that during the perioperative period and on postoperative day 1 . In addition, no significant changes in TOS, TAS, PON1, and arylesterase activities were noticed in Group II. Comparing Group I to Group II, the perioperative TAS level in Group I was significantly higher than the TAS level in Group II ( $\mathrm{p}=0.04)$. In addition, the perioperative arylesterase level of Group I was higher $(\mathrm{p}=0.028)$ than that of Group II.

\section{DISCUSSION}

LC, a minimally invasive, and effective safe technique, has become the gold standard for the surgical management

Table 1 - Leukocyte counts and neutrophil rates of Groups I and II

\begin{tabular}{lccc}
\hline & GROUP I & GROUP II & P \\
\hline Leukocyte counts $\left(\right.$ per $\mathbf{~ m m}^{\mathbf{3}}$ ) & & & \\
$\quad$ Preoperative & $7772.72 \pm 2028.27$ & $7790 \pm 1733.62$ & NS \\
$\quad$ Perioperative & $9027.27 \pm 2470.04$ & $10140 \pm 3641.48$ & NS \\
$\quad$ Postoperative day 1 & $9022.72 \pm 2177.54$ & $9700 \pm 2167.94$ & NS \\
Neutrophil rates (\%) & $59.94 \pm 10.37$ & & \\
$\quad$ Preoperative & $64.8 \pm 12.45$ & $54.97 \pm 19.39$ & NS \\
Perioperative & $70.8 \pm 7.68$ & $68.39 \pm 13.29$ & NS \\
Postoperative day 1 & & $72.63 \pm 7.23$ & NS \\
\hline
\end{tabular}

Abbreviations used: NS, not significant.

Table 2 - Activities of PON1 and arylesterase, as well as TAS and TOS levels, in Groups I and II

\begin{tabular}{|c|c|c|c|c|}
\hline & Preoperative & Perioperative & Postoperative day 1 & $\mathrm{p}$ \\
\hline \multicolumn{5}{|l|}{ GROUP I } \\
\hline $\begin{array}{l}\text { Total Oxidant Status } \\
\left(\mu \mathrm{mol} \mathrm{H}_{2} \mathrm{O}_{2} \text { equiv./L) }\right.\end{array}$ & $20.06 \pm 8.25$ & $22.16 \pm 12.87$ & $21.69 \pm 16.1$ & NS \\
\hline $\begin{array}{l}\text { Total Antioxidant } \\
\text { (mmol Trolox equivalents/L) }\end{array}$ & $6.06 \pm 1.44$ & $5.85 \pm 0.92$ & $5.94 \pm 1.27$ & NS \\
\hline $\begin{array}{l}\text { Paraoxonase } \\
(\mathrm{U} / \mathrm{L})\end{array}$ & $224.55 \pm 133.44$ & $209.15 \pm 107.89$ & $190.35 \pm 97.60$ & $\dagger$ \\
\hline $\begin{array}{l}\text { Arylesterase } \\
(\mathrm{U} / \mathrm{L})\end{array}$ & $157.50 \pm 9.17$ & $155.06 \pm 6.36$ & $154.86 \pm 6.77$ & $\ddagger$ \\
\hline \multicolumn{5}{|l|}{ GROUP II } \\
\hline $\begin{array}{l}\text { Total Oxidant Status } \\
\left(\mu \mathrm{mol} \mathrm{H}_{2} \mathrm{O}_{2} \text { equiv./L) }\right.\end{array}$ & $18.3 \pm 8.16$ & $20.07 \pm 13.2$ & $27.55 \pm 22.56$ & NS \\
\hline $\begin{array}{l}\text { Total Antioxidant } \\
\text { (mmol Trolox equivalents/L) }\end{array}$ & $5.19 \pm 0.85$ & $5.13 \pm 0.92$ & $6.18 \pm 1.56$ & NS \\
\hline $\begin{array}{l}\text { Paraoxonase } \\
(\mathrm{U} / \mathrm{L})\end{array}$ & $184.84 \pm 130.45$ & $171.77 \pm 76.14$ & $178.74 \pm 109.39$ & NS \\
\hline $\begin{array}{l}\text { Arylesterase } \\
(\mathrm{U} / \mathrm{L})\end{array}$ & $150.72 \pm 3.99$ & $150.06 \pm 3.36$ & $150.56 \pm 3.24$ & NS \\
\hline
\end{tabular}

$\dagger$ indicates a significant difference in paroxonase activity in Group I during the preoperative period vs. postoperative day $1(\mathrm{p}=0.035)$.

$\$$ indicates a significant difference in arylesterase activity in Group I during the preoperative period vs. perioperative period $(\mathrm{p}=0.024)$ and during the preoperative period vs. postoperative day $1(\mathrm{p}=0.046)$. 
of cholelithiasis. ${ }^{1}$ Nevertheless, laparoscopy has its disadvantages, which are mostly due to an increase in IAP due to pneumoperitoneum. The increase in IAP due to pneumoperitoneum adversely affects the patient's homeostasis. IAP causes significant changes in the cardiovascular and respiratory systems. IAP decreases perfusion in abdominal organs, decreases blood flow in the inferior vena cava and increases the risk of thrombotic disease..$^{2-11}$

The evaluation of oxidative stress can indirectly reflect the changes in microcirculation in the splanchnic area during insufflation in LC. Different oxidative stress markers have been investigated, including nitric oxide; levels of tissue and blood malondialdehyde and total antioxidant; and levels of thiobarbituric acid reactive substances to assess lipid peroxidation, protein carbonyl content, and protein sulfhydryl. In addition to these methods, lipid peroxidation has been used to reflect oxidative stress and total glutathione has been used to reflect actions against oxidative stress. ${ }^{12-15,28,29}$

PON1, a high-density lipoprotein (HDL)-associated enzyme, has many enzymatic activities, including those associated with paraoxonase, arylesterase, dyazoxonase and $\mathrm{Ca}^{2+}$-dependent serum esterase. ${ }^{30,31}$ Decreased PON1 activity was observed in patients with different diseases, including coronary artery disease, hypercholesterolemia, type 2 diabetes or iron-deficiency anemia. ${ }^{32-34}$ Decreased serum PON1 activities in different types of cancers (including lung, pancreatic, gastric, esophageal and prostate) have also been demonstrated. ${ }^{35-39}$

To the best of our knowledge, paraoxonase and arylesterase, as known antioxidants, have not been evaluated in patients who underwent LC. The purpose of the present study was to evaluate the associations between pneumoperitoneum in LC with PON1 activity, arylesterase activity, TAS and TOS.

Thiobarbituric acid-reactive substances are markers of free radical production. In a study by Glantzounis et al., plasma TAS levels were measured preoperatively, 5 minutes after deflation of the pneumoperitoneum or at the end of the operation and $24 \mathrm{~h}$ postoperatively. ${ }^{12}$ A significant elevation in the concentration of thiobarbituric acidreactive substances was observed in the early postoperative measurements in comparison to the preoperative measurements conducted in the LC group in the present study. TAS and uric acid levels were significantly decreased on postoperative day 1 in comparison to preoperative levels; however, no alterations to the concentrations of thiobarbituric acid-reactive substances were observed in the postoperative period in patients who underwent an open cholecystectomy.
In a study by Zulfikaroglu et al. ${ }^{14}$ the effect of carbon dioxide insufflation on tissue and blood malondialdehyde, TAS, arterial blood gases, blood nitric oxide and endtidal carbon dioxide volume were examined. The total operation times for LC patients and open cholecystectomy patients were 46 and 53 minutes, respectively. Blood malondialdehyde levels were higher after 30 minutes in comparison to their levels on postoperative day 1 in both groups examined in the present study. In contrast, TAS levels did not change significantly. Therefore, we conclude that the antioxidant defense system was less stimulated due to less oxidative stress.

Polat et al. ${ }^{15}$ investigated the effects of different IAPs on lipid peroxidation and protein oxidation status during LC. Thiobarbituric acid-reactive substance levels were used to assess lipid peroxidation and protein carbonyl contents. Protein sulfhydryl groups were also measured to assess protein oxidation status. In a study by Polat et al., the authors concluded that carbon dioxide insufflation could lead to an increased oxidative stress response during LC; however, no difference was found between the two examined groups.

Bukan et al. observed increasing levels of malondialdehyde, as well as nitrite and nitrate levels during both open cholecystectomy and LC. ${ }^{28}$ The oxidative stress increased significantly in both groups; however, LC caused significantly less oxidative stress during surgery. The oxidative stress level returned to preoperative levels more quickly after LC.

In our study, TOS levels in patients that underwent LC slightly increased during the perioperative period and on postoperative day 1 , while TAS levels in this group slightly decreased; however, the changes in the levels of both TOS and TAS were not statistically significant. Of note, PON1 levels were significantly lower on postoperative day 1 than during the preoperative period in the LC group. In addition, arylesterase activity was higher during the preoperative period than during both the perioperative period and on postoperative day 1 in the LC group.

In contrast, no significant changes in TOS, TAS, PON1, and arylesterase activities were observed in Group II. Significant changes in well-known oxidative stress markers, including TOS and TAS, have been previously reported. ${ }^{12,14}$ In our study, no statistically significant changes were observed in the well-known TOS and TAS oxidative stress markers in either group. In recent years, PON1 and arylesterase have been used as oxidative stress markers. In the present study, we observed decreases in these new oxidative stress markers. Therefore, we speculate that this finding may reflect changes in the splanchnic microcirculation caused by pneumoperitoneum during LC. In the present study, we also compared perioperative 
TAS levels in Groups I and II. The perioperative TAS level in Group I was higher than that of Group II ( $\mathrm{p}=0.04$ ). Interestingly, the arylesterase level of Group I was also higher ( $\mathrm{p}=0.028$ ) than the level in Group II. These results support the findings by Bukan et al.

In conclusion, PON1 and arylesterase levels are useful markers for evaluating changes in the oxidative status caused by pneumoperitoneum during laparoscopic procedures. In addition, high TAS and arylesterase activities occur during the perioperative period in patients undergoing LC in comparison to patients experiencing open procedures under general anesthesia. Therefore, LC patients may show less oxidative stress during LC as surgeons become increasingly experienced with this technique and as the technique is improved.

\section{REFERENCES}

1. Kama NA, Kologlu M, Doganay M, Reis E, Atli M, Dolapci M. A risk score for conversion from laparoscopic to open cholecystectomy. Am J Surg. 2001;181:520-5.

2. Sare M, Yilmaz I, Hamamci D, Birincioglu M, Ozmen M, Yesilada O. The effect of carbon dioxide pneumoperitoneum on free radicals. Surg Endosc. 2000;14:649-52.

3. Williams MD, Murr PC. Laparoscopic insufflation of the abdomen depresses cardiopulmonary function. Surg Endosc. 1993;7:12-6.

4. Marathe US, Lilly RE, Silvestry SC, Schauer PR, Davis JW, Pappas TN, et al. Alterations in hemodynamics and left ventricular contractility during carbon dioxide pneumoperitoneum. Surg Endosc. 1996;10:974-8.

5. Kaklamanos IG, Condos S, Merrell RC. Time-related changes in hemodynamic parameters and pressure-derived indices of left ventricular function in a porcine model of prolonged pneumoperitoneum. Surg Endosc. 2000;14:834-8.

6. Dexter SP, Vucevic M, Gibson J, McMahon MJ. Hemodynamic consequences of high- and low-pressure capnoperitoneum during laparoscopic cholecystectomy. Surg Endosc. 1999;13:376-81.

7. Bickel A, Yahalom M, Roguin N, Frankel R, Breslava J, Ivry S, et al. Power spectral analysis of heart rate variability during positive pressure pneumoperitoneum: the significance of increased cardiac sympathetic expression. Surg Endosc 2002;16:1341-4.

8. Eleftheriadis E, Kotzampassi K, Botsios D, Tzartinoglou E, Farmakis H,Dadoukis J. Splanchnic ischemia during laparoscopic cholecystectomy. Surg Endosc. 1996;10: 324-6.

9. Jakimowicz J, Stultiens G, Smulders F. Laparoscopic insufflation of the abdomen reduces portal venous flow. Surg Endosc. 1998;12:129-32.

10. Gudmundsson FF, Gislason HG, Dicko A, Horn A, Viste A, Grong $\mathrm{K}$, et al. Effects of prolonged increased intra-abdominal pressure on gastrointestinal blood flow in pigs. Surg Endosc. 2001;15:854-60.

11. Schilling MK, Redaelli C, Krähenbühl L, Signer C, Büchler MW. Splanchnic microcirculatory changes during CO2 laparoscopy. J Am Coll Surg. 1997; 184:378-82.

12. Glantzounis GK, Tselepis AD, Tambaki AP, Trikalinos TA, Manataki AD, Galaris DA, et al. Laparoscopic surgery-induced changes in oxidative stress markers in human plasma. Surg Endosc. 2001;15:13159.

13. Seven R, Seven A, Erbil Y, Mercan S, Burçak G. Lipid peroxidation and antioxidant state after laparoscopic and open cholecystectomy. Eur J Surg. 1999;165:871-4.
14. Zulfikaroglu B, Koc M, Soran A, Isman FK, Cinel I. Evaluation of oxidative stress in laparoscopic cholecystectomy. Surg Today. 2002;32:869-74.

15. Polat C, Yilmaz S, Serteser M, Koken T, Kahraman A, Dilek ON. The effect of different intraabdominal pressures on lipid peroxidation and protein oxidation status during laparoscopic cholecystectomy. Surg Endosc. 2003;17:1719-22.

16. Aviram M, Rosenblat M, Billecke S, Erogul J, Sorenson R, Bisgaier $\mathrm{CL}$, et al. Human serum paraoxonase (PON 1) is inactivated by oxidized low density lipoprotein and preserved by antioxidants. Free Radic Biol Med. 1999;26:892-904

17. Pasqualini L, Cortese C, Marchesi S, Siepi D, Pirro M, Vaudo G, et al. Paraoxonase-1 activity modulates endothelial function in patients with peripheral arterial disease. Atherosclerosis. 2005;183:349-54.

18. Mackness MI, Arrol S, Durrington PN. Paraoxonase prevents accumulation of lipoperoxides in low-density lipoprotein. FEBS Lett. 1991;286:152-4.

19. Aviram M. Introduction to the serial review on paraoxonases, oxidative stress, and cardiovascular diseases. Free Radic Biol Med. 2004;37:1301-

20. Eckerson HW, Wyte CM, La Du BN. The human serum paraoxonase/ arylesterase polymorphism. Am J Hum Genet 1983;35:1126-38.

21. Kotur-Stevuljevic J, Spasic S, Jelic-Ivanovic Z, SpasojevicKalimanovska V, Stefanovic A, Vujovic A, et al. PON1 status is influenced by oxidative stress and inflammation in coronary heart disease patients. Clin Biochem. 2008;41:1067-73

22. Aviram M, Rosenblat M. Paraoxonases and cardiovascular diseases: pharmacological and nutritional influences. Curr Opin Lipidol. 2005;16:393-9

23. Nguyen SD, Sok DE. Oxidative inactivation of paraoxonase1, an antioxidant protein and its effect on antioxidant action. Free Radic Res. 2003;37:1319-30

24. Rozenberg O, Aviram M. S-Glutathionylation regulates HDL-associated paraoxonase 1 (PON1) activity. Biochem Biophys Res Commun. 2006;351:492-8.

25. Haagen L, Brock A. A new automated method for phenotyping arylesterase (EC 3.1.1.2.) based upon inhibition of enzymatic hydrolysis of 4-nitrophenyl acetate by phenyl acetate. Eur J Clin Chem Clin Biochem. 1992:30:391-5. 
26. Erel O. A novel automated direct measurement method for total antioxidant capacity using a new generation, more s ABTS radical cation. Clin Biochem. 2004;37:277-85.

27. Erel O. A new automated colorimetric method for measuring total oxidant status. Clin Biochem. 2005;38:1103-11.

28. Bukan MH, Bukan N, Kaymakcioglu N, Tufan T. Effects of open vs. laparoscopic cholecystectomy on oxidative stress. Tohoku J Exp Med. 2004;202:51-6.

29. Bickel A, Drobot A, Aviram M, Eitan A. Validation and reduction of the oxidative stress following laparoscopic operations: a prospective randomized controlled study. Ann Surg. 2007;246:31-55.

30. Mackness B, Durrington PN, Mackness MI. Human serum paraoxonase. Gen. Pharmacol. 1998;31:329-36.

31. Canales A, Sanchez-Muniz FJ. Paraoxanase, something more than an enzyme? Med. Clin. (Barc) 2003;121:537-48.

32. Ayub A, Mackness MI, Arrol S, Mackness, Patel BJ, Durrington PN Serum paraoxonase after myocardial infarction, Arterioscler. Thromb. Vasc. Biol. 1999;19: 330-5.

33. Mackness MI, Harty D, Bhatnagar D, Winocour PH, Arrol S, Ishola M, et al. Serum paraoxonase activity in familial hypercholesterolemia and insulin-dependent diabetes mellitus. Atherosclerosis. 1992;86:193-9.
34. Aslan M, Kosecik M, Horoz M, Selek S, Celik H, Erel O. Assessment of paraoxonase and arylesterase activities in patients with iron deficiency anemia, Atherosclerosis. 2007;191:397-402.

35. Elkiran TE, Mar N, Aygen B, Gursu F, Karaoglu A, Koca S. Serum paraoxonase and arylesterase activities in patients with lung cancer in a Turkish population. BMC Cancer. 2007;7:48.

36. Akcay MN, Polat MF, Yilmaz I, Akcay G. Serum paraoxonase levels in pancreatic cancer, Hepatogastroenterology 2003;50 (Supply 2): ccxxv-ccxxvii.

37. Akcay MN, Polat MF, Yilmaz I, Akcay G. Serum paraoxonase levels in gastric cancer, Hepatogastroenterology 2003b;50 (Supply 2): cclxxiiicclxxv.

38. Krzystek-Korpacka M, Boehm D, Matusiewicz M, Diakowska D, Grabowski K, Gamian A.. Paraoxonase 1 (PON1) status in gastroesophageal malignancies and associated paraneoplastic syndromes - connection with inflammation. Clin Biochem. 2008;41:804-11.

39. Stevens VL, Rodriguez C, Talbot JT, Pavluck MJ, Thun MJ, Calle EE. Paraoxonase 1 (PON1) polymorphisms and prostate cancer in the CPS-II Nutrition Cohort. Prostate. 2008;68:1336-40. 